\title{
Recent changes in the Dutch foodscape: socioeconomic and urban-rural differences
}

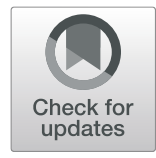

\author{
Maria Gabriela M. Pinho ${ }^{1 *}$ D, Joreintje D. Mackenbach ${ }^{1}$, Nicole R. den Braver ${ }^{1}$, Joline J. W. Beulens ${ }^{1,2}$, \\ Johannes Brug ${ }^{1,3}$ and Jeroen Lakerveld ${ }^{1,3,4}$
}

\begin{abstract}
Background: Obesogenic food environments may influence dietary behaviours and contribute to obesity. Few countries quantified changes in their foodscape. We explored how the availability of different types of food retailers has changed in the Netherlands across levels of neighbourhood socioeconomic status (SES) and urbanisation.

Methods: This longitudinal ecological study conducted in the Netherlands had as unit of analysis administrative neighbourhoods. From 2004 to 2018, the geographic location and type of each food retailer were objectively assessed by a commercial company. Food retailers were categorised as local food shops, fast food restaurants, food delivery, restaurants, supermarkets, and convenience stores. Information on neighbourhood SES and urbanisation was obtained from Central Bureau of Statistics (CBS). To test the change in the counts of food retailers we used negative binomial generalized estimating equations (GEE), with neighbourhoods as the group variable, time as the independent variable and the counts of each type of food retailer as outcome. To account for changes in population density, analyses were adjusted for the number of inhabitants per neighbourhood. We tested effect modification by adding an interaction term for neighbourhood SES and urbanisation to the models.

Results: In Dutch neighbourhoods between 2004 and 2018, a 120 and 35\% increase was found in the count of food delivery outlets and restaurants, respectively, and a $24 \%$ decrease in count of local food shops. Stratified analyses showed an increase in the availability of supermarkets and convenience stores in the more urbanised and lower SES neighbourhoods, while a decrease was observed in the less urbanised and higher SES neighbourhoods.

Conclusions: We observed considerable changes in the Dutch foodscape. Over a 14 years period, the foodscape changed towards a higher availability of food retailers offering convenience and ready-to-eat foods. These findings can help policy makers aiming to promote a healthier food environment and obesity prevention.
\end{abstract}

\section{Background}

Current dietary patterns in developed countries are characterized by a great share of energy-dense and high in fat, salt or sugar foods, and high consumption of animal food products and ultra-processed foods. Intakes of fruits and vegetables, fibre and fresh products are generally low and the preparation of home-cooked meals is

\footnotetext{
* Correspondence: m.matiasdepinho@vumc.nl

'Department of Epidemiology and Biostatistics, Amsterdam Public Health Research Institute, Amsterdam UMC, Vrije Universiteit Amsterdam, de Boelelaan 1089A, 1081, BT, Amsterdam, The Netherlands

Full list of author information is available at the end of the article
}

decreasing [1-4]. Changes in the food environment may be an important driver of unhealthy dietary patterns and their related health consequences such as obesity, type 2 diabetes and cardiovascular diseases [5-7].

The foodscape, i.e., the distribution of food retailers across a determined geographical area, is an important aspect of the food environment [8]. Food environments providing a great amount of opportunities to obtain unhealthy foods may be classified as an 'obesogenic' environment, which contributes to population weight gain [9]. Few countries have been able to quantify changes in their foodscape [10-12]. Evidence suggests

\section{$\triangle B M C$}

(c) The Author(s). 2020 Open Access This article is licensed under a Creative Commons Attribution 4.0 International License, which permits use, sharing, adaptation, distribution and reproduction in any medium or format, as long as you give appropriate credit to the original author(s) and the source, provide a link to the Creative Commons licence, and indicate if changes were made. The images or other third party material in this article are included in the article's Creative Commons licence, unless indicated otherwise in a credit line to the material. If material is not included in the article's Creative Commons licence and your intended use is not permitted by statutory regulation or exceeds the permitted use, you will need to obtain permission directly from the copyright holder. To view a copy of this licence, visit http://creativecommons.org/licenses/by/4.0/ The Creative Commons Public Domain Dedication waiver (http://creativecommons.org/publicdomain/zero/1.0/) applies to the data made available in this article, unless otherwise stated in a credit line to the data. 
that some aspects of the foodscape may change relatively quickly, and that the window of change as well as the type of change may differ according to neighbourhood socioeconomic status $[10,12,13]$. Although obesity rates in the Netherlands are lower than in most other countries that are part of the Organisation for Economic Cooperation and Development, the prevalence of obesity has doubled over a period of 20 years [14], and a changing food environment may have contributed to this increase. While research from the Netherlands found evidence for a link between the food environment and dietary patterns and non-communicable diseases [15, 16], no studies have been published to date on how the Dutch foodscape has changed over time. Insight on how the foodscape has changed may be valuable to understand results found in current literature, design new studies as well as policies that aim to facilitate a healthier food environment.

Recent developments such as ongoing urbanisation, differences in levels of affluence, time restraints a growing need for convenience and information technology developments are likely to influence changes in the foodscape. As such, the aim of this study was to analyse if and how the availability of different types of food retailers, adjusted for the number of inhabitants per neighbourhood, has changed between 2004 and 2018, and to explore whether this change (if any) was different according to neighbourhood socioeconomic status (SES) and urbanisation levels.

\section{Methods}

This longitudinal ecological study was conducted across the Netherlands. The units of analysis in this study were administrative neighbourhoods as defined by Central Bureau of Statistics (CBS) of the Netherlands. In order to avoid including nonresidential areas -such as natural reserves, neighbourhoods composed mostly of water or big industrial areas-, we included only neighbourhoods with at least 100 inhabitants in the analysis. The median number of inhabitants per neighbourhood in 2004 was 910 (interquartile range $=330-2230$ ) and 2018 it was 985 (interquartile range $=370-2050$ ). Neighbourhood areas in turn, ranged from 0.01 to 131.58 squarekilometres $\left(\mathrm{km}^{2}\right)$ in 2004 , and from 0.02 to 130.14 $\mathrm{km}^{2}$ in 2018. The number of neighbourhoods analysed each year was not constant as new neighbourhoods emerged and others ceased to exist. Potential changes in some of the neighbourhood boundaries may have occurred. However, CBS annually publishes shapefiles with updated neighbourhood characteristics, as we used these files with updated neighbourhood information for each year, changes on neighbourhood characteristics, such as boundaries, were taken into account in our analysis. In addition, analyses were adjusted for the number of inhabitants per neighbourhood, taking into account changes in the population density.

\section{Data sources \\ Food environment}

The location of all food retailers was determined via geographic coordinates as collected by an independent Dutch company that collects objective data on the Dutch retail landscape (Locatus, https://locatus.com/en/). Since 2004, Locatus systematically performs regular field audits to map the locations and types of stores for commercial purposes; thus, the geographical location of any retailer in the Netherlands is determined. The frequency of field audits varies from once a year - in shopping areas - to once every 2 or 3 years in regions located outside shopping areas. For this study, we included retailers of which the primary activity was to sell food or meals, and excluded other types of retailers that may sell foods as a secondary activity, such as gas stations and drugstores. The validity of Locatus data was tested against a field audit in selected areas across the Netherlands in 2019. This validation study showed the location and classification of grocery stores (e.g., supermarkets, local food shops, green grocers) and food outlets (e.g. restaurants, fast food restaurants) was "good" to "excellent. A kappa value of 0.58 for all food outlets combined was found, showing 'good' agreement. However, there were differences in Kappa values across specific food retailer categories. For instance, Kappa values were 0.62 for confectionary stores, 0.92 for supermarkets and 0.95 for fast food retailers. (Canalia 2019, in preparation). Therefore, the Locatus database was considered to be a credible source of data on the locations and classifications of food retailers in the Netherlands. It is worth to note that although Locatus data was considered a secondary data source for this validation study, the data is primarily collected via objective field audits, which is the preferable method for acquisition of geographical data on the location of food retailers.

In the current analysis, food retailers were aggregated into the following categories: local food shops; fast food restaurants; food delivery outlets; restaurants; supermarkets; and convenience stores. Regarding the classification of food retailers, while there are many retailers that have dual purposes (e.g. a fullservice restaurant that also do meal delivery), in the Locatus dataset, retailers are classified on the basis of their main purpose. An example is the category 'food delivery outlets', which includes solely food retailers that do delivery as their main activity. Similarly, restaurants that provide delivery services are not 
accounted for in the food delivery category as their main activity is to serve meals at the table. Table 1 provides more detail on the composition of each food retailer category.

\section{Neighbourhood level of urbanisation and SES}

Based on the density of residential addresses per $\mathrm{km}^{2}$, CBS defines 5 levels of urbanisation. Due to the distribution of the urbanisation variable, which had fewer neighbourhoods in the categories indicating highest, high and moderate urbanisation (the highest three categories), we aggregated these categories. By combining these three categories, we obtained a comparable number of observations as in the least urbanised category. Thus, the highest urbanisation category obtained was composed of areas with 1000 addresses or more per $\mathrm{km}^{2}$, and the lowest urbanisation category was composed of areas with less than 500 addresses per $\mathrm{km}^{2}$.

Information on neighbourhood SES was obtained from the CBS website. Moudon and colleagues (2011), proposed a metric of neighbourhood wealth, which can be derived as a single variable indicating neighbourhood property values, as being a good predictor of individual health status. This metric is considered to be a good proxy of area-based SES in studies that analyse contextual influences on health [17]. Therefore, the average value of residential properties per neighbourhood per year was used as a proxy for neighbourhood SES. Because in 2018 housing prices were not yet available at the time of analysis, the average housing price per neighbourhood in
2017 was used for 2018. In order to obtain a similar variable as the neighbourhood urbanisation variable, the continuous variables for average housing price (neighbourhood SES) were split into quintiles, with the first quintile being composed of the lowest values for average house prices (lowest neighbourhood SES) and the fifth quintile representing the highest values for average house prices (highest neighbourhood SES).

For these analyses, only the top and bottom categories of neighbourhood SES and urbanisation were considered. In the results section we present a table describing the percentage of neighbourhoods in each SES and urbanisation category.

\section{Statistical analysis}

To obtain the counts of food retailers per neighbourhood, we intersected a layer in ArcGIS ${ }^{\circ}$ containing the location of food retailers to a layer containing the neighbourhood information. Food environment data is typically zero inflated, which usually leads to over-dispersion of the data. Ideally, we would analyse our count data using a zero inflated negative binomial model. However, since we wanted to model 'time' as independent variable at the population average level this was not possible, and therefore the generalized estimating equations (GEE) was deemed to be the most suitable. Within the GEE models, both Poisson and Negative binomial models suited our count data. We chose the GEE negative binomial approach because, although it does not account completely for the zero inflated nature of the data (as the zero inflated negative binomial model would), this model does account for over-

Table 1 Analysed categories of food retailers

\begin{tabular}{|c|c|c|}
\hline Analytical category & Food retailers composing the analytical category & Definition of food retailers and/or main food products offered by them \\
\hline \multirow[t]{5}{*}{ Local food shops } & Greengrocers & Main provision of potatoes, vegetables and fruit \\
\hline & Butchery & Main provision of meat and meat products \\
\hline & Poultry shop & Main provision of poultry \\
\hline & Bakery & $\begin{array}{l}\text { Main provision of bread and pastries. Table service is possible, } \\
\text { but this is not be the main store activity }\end{array}$ \\
\hline & Fish stores & Main provision of fish, crustaceans and molluscs \\
\hline Fast food restaurants & $\begin{array}{l}\text { Fast food chains and locally } \\
\text { owned fast food restaurants }\end{array}$ & $\begin{array}{l}\text { Main provision of mostly deep-fried products that are ready for } \\
\text { consumption in few minutes after ordering. Usually there is no } \\
\text { table service available. }\end{array}$ \\
\hline Food delivery & $\begin{array}{l}\text { Food delivery } \\
\text { Take away }\end{array}$ & $\begin{array}{l}\text { Main provision of meals that are not consumed in the store, but } \\
\text { are collected or delivered }\end{array}$ \\
\hline \multirow[t]{3}{*}{ Restaurants } & Restaurant & $\begin{array}{l}\text { Main provision of meals a-la-carte, table service is present. Drinks } \\
\text { are only provided in combination with food }\end{array}$ \\
\hline & Café-restaurant & Main provision of both drinks and simple meals \\
\hline & Restaurant in hotels & $\begin{array}{l}\text { Main provision of overnight accommodation in combination with } \\
\text { an a-la-carte restaurant }\end{array}$ \\
\hline Supermarket & Supermarket & $\begin{array}{l}\text { Store selling a wide range of food and non-food products which } \\
\text { are used on a daily bases. Store size should be at least } 150 \mathrm{~m}^{2}\end{array}$ \\
\hline Convenience stores & Convenience stores & Same as supermarkets but store size is less than $150 \mathrm{~m}^{2}$ \\
\hline
\end{tabular}


dispersion. Thus, to test the average change in the count of food retailers from 2004 to 2018, we used negative binomial GEE models with the neighbourhood as the group variable, dummy variables for each year as independent variable and the counts of each food retailer as the outcome in separate models. For these analyses, 2004 was considered the baseline value and yearly changes were compared to 2004.

Because variation in the count of food retailers could reflect variation in population density over time, we adjusted our models for the number of inhabitants per neighbourhood. We also tested whether the average change in the count of food retailers was different according to neighbourhood SES and urbanisation. For this purpose, we tested effect modification by adding an interaction term between 'year' and 'neighbourhood SES' or 'urbanisation' to each model. Given the large number of neighbourhoods, significant interaction was considered with $p<0.001$. Because we expected a high correlation between SES and urbanisation variables, we analysed the percentage of overlapping neighbourhoods across the categories of neighbourhood SES and urbanisation by running a cross-tabulation table. Also because of this high correlation between SES and urbanisation variables, potentially leading to multi-collinearity, models were run separately, i.e., we did not control for SES in the urbanisation model and vice-versa.

Statistical analyses were conducted in STATA and graphs were produced in RStudio using ggplot2 packages. No smoothing method was applied.

\section{Results}

The total number of neighbourhoods per year included in the analysis ranged from 9956 (in 2004) to 11,751 (in 2018). Some neighbourhoods emerged and others ceased to exist over time, affecting the number of neighbourhood observations per year. All neighbourhood observations over the 14 analysed years summed to a total of 151,150 observations. As in the GEE analysis each neighbourhood observed at least once over the 14 years period counts as one unit of analysis, the final analysed number of neighbourhoods was 15,394 . Table 2 shows descriptive neighbourhood statistics at baseline. The maximum number of food retailers per neighbourhood in 2004 was 228 , ranging from a maximum number of seven supermarkets to a maximum number of 121 restaurants per neighbourhood. In total, there were $37.8 \%$ neighbourhoods with no food retailer present, the amount of 'empty' neighbourhoods was higher for highest SES $(53.0 \%)$ and lowest urbanised neighbourhoods (48\%). The median counts of food retailers were mostly zero for the totality of neighbourhoods and also by lowest and highest categories of neighbourhood SES and urbanisation. However, when looking at neighbourhoods with at least one food retailer present, and considering the interquartile ranges, the average counts of all types of food retailers were higher in the low SES and the highly urbanised neighbourhoods than in the high SES and the low urbanised neighbourhoods. Table 3 shows the distribution of neighbourhoods according to neighbourhood SES and urbanisation level. We observed that $75.5 \%$ of the lowest SES neighbourhoods were also the highest urbanised neighbourhoods, and $69.3 \%$ of all highest SES neighbourhoods were also the least urbanised neighbourhoods.

Figure 1 shows the average change in the counts per neighbourhood of the various types of food retailers in the Netherlands. The biggest changes were observed for food delivery places, restaurants and local shops. Neighbourhoods in 2018, as compared to 2004, had a $120 \%$ increase in the count of food delivery outlets (incidence rate ratio $(\mathrm{IRR})=2.22,95 \%$ confidence interval $(\mathrm{CI})=$ $2.04-2.41) ; 35 \%$ increase in the counts of restaurants $(\mathrm{IRR}=1.35,95 \% \mathrm{CI}=1.30-1.40)$; and $24 \%$ decrease in count of local shops (IRR $=0.76,95 \% \mathrm{CI}=0.74-0.79$ ). A weaker increase was observed for convenience stores $(\mathrm{IRR}=1.13,95 \% \mathrm{CI}=1.04-1.23)$ and fast food restaurants (IRR $=1.06,95 \% \mathrm{CI}=1.02-1.10$ ) in 2018 as compared to 2004. For counts of supermarkets, no significant change was observed in 2018 as compared to 2004 $(\mathrm{IRR}=1.01,95 \% \mathrm{CI}=0.98-1.04)$.

Significant effect modification $(p<0.001)$ was observed for a change in the availability of convenience stores and supermarkets across lowest and highest neighbourhood SES and urbanisation. Figure 2 shows stratified analyses by neighbourhood SES. The count of both convenience stores and supermarkets was higher in the lowest SES neighbourhoods over the entire study period, with the average counts of convenience stores increasing $58 \%(\mathrm{IRR}=1.58,95 \% \mathrm{CI}=1.38-1.80)$ in the lowest, and decreasing $46 \%$ (IRR $=0.54,95 \% \mathrm{CI}=0.43$ 0.68) in the highest SES neighbourhood strata in 2018 as compared to 2004. For supermarkets, an increase of $10 \%$ and a decrease of $29 \%$ was observed for lowest $(\mathrm{IRR}=1.10,95 \% \mathrm{CI}=1.03-1.17)$ and highest $(\mathrm{IRR}=0.71$, 95\%CI $=0.61-0.84)$ SES neighbourhood, respectively. Food delivery places increased in both lowest (IRR = $2.15,95 \% \mathrm{CI}=1.90-2.44)$ and highest $(\mathrm{IRR}=3.00$, $95 \% \mathrm{CI}=2.32-3.87)$ SES neighbourhoods. Although the average counts of food delivery outlets were higher for the highest SES neighbourhoods over the entire study period, no effect modification by neighbourhood SES was found. Local shops decreased and restaurants increased from 2004 to 2018, but there were no differences across lowest and highest SES neighbourhoods and the effect sizes across both neighbourhood types were very similar: local shops had a 29 and $22 \%$ 
Table 2 Descriptive baseline characteristics of neighbourhoods

\begin{tabular}{|c|c|c|c|c|}
\hline & $\begin{array}{l}\text { Counts } \\
\text { Min-Max }\end{array}$ & $\begin{array}{l}\text { Median (IQR) } \\
\text { All neighbourhoods }\end{array}$ & $\begin{array}{l}\text { Neighbourhoods with } \\
\text { zero food retailer of } \\
\text { each type (\%) }\end{array}$ & $\begin{array}{l}\text { Median (IQR) -excluding } \\
\text { neighbourhoods with zero } \\
\text { food retailers }\end{array}$ \\
\hline \multicolumn{5}{|c|}{ Total neighbourhoods in $2004(n=9956)$} \\
\hline Total counts of food retailers & $0-228$ & $1(0-4)$ & $37.8 \%$ & $3(1-7)$ \\
\hline Counts of fast food restaurants & $0-35$ & $0(0-1)$ & $65.5 \%$ & $1(1-2)$ \\
\hline Counts of food delivery places & $0-16$ & $0(0-0)$ & $91.9 \%$ & $1(1-2)$ \\
\hline Counts of supermarkets & $0-7$ & $0(0-1)$ & $70.3 \%$ & $1(1-2)$ \\
\hline Counts of local shops & 0-39 & $0(0-1)$ & $67.2 \%$ & $2(1-4)$ \\
\hline Counts of restaurants & $0-121$ & $0(0-1)$ & $60.6 \%$ & $1(1-3)$ \\
\hline Counts of convenience stores & $0-10$ & $0(0-0)$ & $90.4 \%$ & $1(1-1)$ \\
\hline Inhabitants per neighbourhood & $100-27,500$ & $910(330-2230)$ & - & - \\
\hline \multicolumn{5}{|c|}{ Lowest neighbourhood SES in $2004(n=1936)$} \\
\hline Total counts of food retailers & $0-157$ & $3(0-8)$ & $25.2 \%$ & $5(2-11)$ \\
\hline Counts of fast food restaurants & $0-24$ & $1(0-2)$ & $46.6 \%$ & $2(1-3)$ \\
\hline Counts of food delivery places & $0-8$ & $0(0-0)$ & $82.3 \%$ & $1(1-2)$ \\
\hline Counts of supermarkets & $0-7$ & $0(0-1)$ & $54.7 \%$ & $1(1-2)$ \\
\hline Counts of local shops & $0-39$ & $0(0-2)$ & $50.5 \%$ & $2(1-5)$ \\
\hline Counts of restaurants & $0-77$ & $0(0-1)$ & $55.5 \%$ & $2(1-3)$ \\
\hline Counts of convenience stores & $0-10$ & $0(0-0)$ & $81.6 \%$ & $1(1-2)$ \\
\hline Inhabitants per neighbourhood & $100-27,500$ & $1645(760-3140)$ & - & - \\
\hline \multicolumn{5}{|c|}{ Highest neighbourhood SES in $2004(n=1875)$} \\
\hline Total counts of food retailers & $0-170$ & $0(0-2)$ & $53.0 \%$ & $2(1-3)$ \\
\hline Counts of fast food restaurants & $0-19$ & $0(0-0)$ & $87.9 \%$ & $1(1-1)$ \\
\hline Counts of food delivery places & $0-8$ & $0(0-0)$ & $98.3 \%$ & $1(1-2)$ \\
\hline Counts of supermarkets & $0-3$ & $0(0-0)$ & $90.2 \%$ & $1(1-1)$ \\
\hline Counts of local shops & $0-16$ & $0(0-0)$ & $87.4 \%$ & $1(1-2)$ \\
\hline Counts of restaurants & $0-98$ & $0(0-1)$ & $67.5 \%$ & $1(1-2)$ \\
\hline Counts of convenience stores & $0-3$ & $0(0-0)$ & $94.9 \%$ & $1(1-1)$ \\
\hline Inhabitants per neighbourhood & $100-11,430$ & $340(200-680)$ & - & \\
\hline \multicolumn{5}{|c|}{ Lowest neighbourhood urbanisation in $2004(n=4554)$} \\
\hline Total counts of food retailers & $0-55$ & $1(0-2)$ & $48.8 \%$ & $2(1-4)$ \\
\hline Counts of fast food restaurants & $0-7$ & $0(0-0)$ & $81.8 \%$ & $1(1-2)$ \\
\hline Counts of food delivery places & $0-1$ & $0(0-0)$ & $99.1 \%$ & $1(1-1)$ \\
\hline Counts of supermarkets & $0-3$ & $0(0-0)$ & $80.4 \%$ & $1(1-1)$ \\
\hline Counts of local shops & $0-8$ & $0(0-0)$ & $79.4 \%$ & $1(1-2)$ \\
\hline Counts of restaurants & $0-34$ & $0(0-1)$ & $66.9 \%$ & $1(1-2)$ \\
\hline Counts of convenience stores & $0-3$ & $0(0-0)$ & $93.7 \%$ & $1(1-1)$ \\
\hline Inhabitants per neighbourhood & $100-5220$ & $390(200-820)$ & - & - \\
\hline \multicolumn{5}{|c|}{ Highest neighbourhood urbanisation in $2004(n=3576)$} \\
\hline Total counts of food retailers & $0-228$ & $3(0-8)$ & $28.4 \%$ & $5(2-12)$ \\
\hline Counts of fast food restaurants & $0-35$ & $1(0-2)$ & $47.1 \%$ & $2(1-3)$ \\
\hline Counts of food delivery places & $0-16$ & $0(0-0)$ & $81.0 \%$ & $1(1-2)$ \\
\hline Counts of supermarkets & $0-7$ & $0(0-1)$ & $58.0 \%$ & $1(1-2)$ \\
\hline Counts of local shops & $0-39$ & $0(0-3)$ & $51.3 \%$ & $3(1-5)$ \\
\hline Counts of restaurants & $0-121$ & $0(0-2)$ & $56.2 \%$ & $2(1-4)$ \\
\hline Counts of convenience stores & $0-10$ & $0(0-0)$ & $84.3 \%$ & $1(1-2)$ \\
\hline Inhabitants per neighbourhood & $100-27,500$ & $2010(1070-13,630)$ & - & - \\
\hline
\end{tabular}


Table 3 Distribution of neighbourhoods according to neighbourhood socioeconomic status (SES) and urbanisation levels

\begin{tabular}{|c|c|c|c|c|c|c|}
\hline \multicolumn{2}{|c|}{ Neighbourhood SES } & \multicolumn{5}{|c|}{ Urbanisation } \\
\hline & & \multicolumn{3}{|c|}{ Highest $^{a}$} & \multirow[b]{2}{*}{4} & \multirow{2}{*}{$\begin{array}{l}\text { Lowest } \\
5\end{array}$} \\
\hline & & 1 & 2 & 3 & & \\
\hline \multirow[t]{4}{*}{ Lowest } & $1\left(n=27,877^{b}\right)$ & $26.7 \%$ & $33.2 \%$ & $15.6 \%$ & $8.7 \%$ & $16.0 \%$ \\
\hline & $2\left(n=27,735^{b}\right)$ & $15.2 \%$ & $25.6 \%$ & $17.1 \%$ & $16.0 \%$ & $26.2 \%$ \\
\hline & $3\left(n=27,644^{b}\right)$ & $7.8 \%$ & $17.9 \%$ & $16.6 \%$ & $19.1 \%$ & $38.6 \%$ \\
\hline & $4\left(n=27,511^{b}\right)$ & $5.5 \%$ & $10.1 \%$ & $12.6 \%$ & $18.0 \%$ & $53.8 \%$ \\
\hline Highest & $5\left(n=27,523^{b}\right)$ & $3.9 \%$ & $5.9 \%$ & $7.2 \%$ & $13.6 \%$ & $69.3 \%$ \\
\hline
\end{tabular}

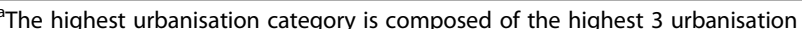
levels as defined by the Central Bureau of Statistics (CBS). Values in bold represent the overlap between lowest and highest categories of neighbourhood SES and urbanisation

${ }^{\mathrm{b}}$ Number of observations for neighbourhood SES across the 14 years period, this includes observations for neighbourhoods that ceased to exist or were created during the study period. For all the study years, lowest urbanisation category is composed of neighbourhoods with $<500$ addresses $/ \mathrm{km}^{2}$; highest urbanisation category is composed of neighbourhoods with $\geq 1000$ addresses/ $\mathrm{km}^{2}$. Lowest SES category is composed of neighbourhoods with an average house value ranging from EUR 25,000 to EUR 191,000; Highest SES category is composed of neighbourhoods with an average house value of EUR 209,000 or higher

decrease for lowest and highest SES neighbourhood respectively, and restaurants had approximately 30\% increase in both neighbourhood types. While average count of fast food restaurants was higher for the lowest SES neighbourhood over the study period, no significant change was observed in both lowest and highest SES neighbourhood from 2004 to 2018.

Figure 3 shows the results of stratified analyses by urbanisation level. Similar to the analysis stratified by neighbourhood SES, significant effect modification $(p<$ 0.001 ) was observed for a change in the availability of convenience stores and supermarkets across lowest and highest levels of urbanisation. In 2018, as compared to 2004, counts of convenience stores increased by $50 \%$ (IRR = $1.50,95 \% \mathrm{CI}=1.35-1.66)$ and supermarkets increased by $13 \%(\mathrm{IRR}=1.13,95 \% \mathrm{CI}=1.08-1.18)$ in the highest urbanised neighbourhoods. In the lowest urbanised neighbourhoods, convenience stores decreased 64\% (IRR $=0.36,95 \%$ $\mathrm{CI}=0.29-0.45)$ and supermarkets decreased $26 \%$ (IRR = $0.74,95 \% \mathrm{CI}=0.69-0.79$ ). Food delivery places and restaurants increased in both levels of urbanisation. Food delivery outlets had a $154 \%$ increase in the lowest (IRR = $2.54,95 \% \mathrm{CI}=1.75-3.68)$ and a $116 \%$ increase in the highest urbanised neighbourhoods (IRR $=2.16,95 \% \mathrm{CI}=1.98$ 2.36). Restaurants increased $41 \%$ in the lowest (IRR $=1.41$, $95 \% \mathrm{CI}=1.34-1.48)$ and $33 \%$ in the highest urbanised neighbourhoods ( $I R R=1.33,95 \% \mathrm{CI}=1.26-1.40$ ). For fast food restaurants, while no significant effect modification was found, in the stratified analysis a small increase of $7 \%$ was observed in the highest urbanised neighbourhoods $(\mathrm{IRR}=1.07,95 \% \mathrm{CI}=1.02-1.12)$. Similarly, no differences across levels of urbanisation were observed for local shops as a decrease of about $25 \%$ was observed for both lowest $(\mathrm{IRR}=0.76,95 \% \mathrm{CI}=0.71-0.81)$ and highest $(\mathrm{IRR}=0.74$, $95 \% \mathrm{CI}=0.70-0.77)$ urbanisation levels.

\section{Discussion}

In this study we analysed changes in the Dutch foodscape over the years 2004 to 2018 and explored whether these changes were different according to neighbourhood SES and levels of urbanisation. Independent of neighbourhood SES and urbanisation, we found a remarkable increase in the availability of food delivery outlets, restaurants and to a lesser extent in fast food restaurants. A general decrease was observed in the availability of local food shops. While in the general analysis, the availability of supermarkets and convenience stores did not seem to change, this apparent null effect was most likely due to effect modification by neighbourhood SES and urbanisation levels. Indeed, in the stratified analysis, more urbanised as well as lower SES neighbourhoods showed an increase in the availability of supermarkets and convenience stores, while a decrease was observed in the less urbanised and higher SES neighbourhoods.

Not many studies to date have analysed trends in the foodscape. In addition, previous studies investigated different kinds of food retailers, used different classifications, or are from countries depicting a different foodscape than in the Netherlands $[11,12]$. Nonetheless, a study from the UK found a general increase of $45 \%$ in the availability of takeaway outlets over an 18 years period, while a stronger increase of $120 \%$ was observed in our study for food delivery places, which included takeaway outlets. Also, they found an increase in the availability of supermarkets, while in our study the availability of supermarkets remained constant in the general analysis [12]. Similar to our findings, a study from the US observed an increase in the availability of restaurants and fast food restaurants and a decrease in the availability of independent grocery stores, while the availability of supermarkets remained relatively constant. Also, they observed an increase in the availability of bakeries, while in our study, bakeries were part of the local shop category, which generally decreased over time [11]. These general trends of increasing availability of food delivery outlets and restaurants and the decreased availability of local shops are in line with previous changes in dietary patterns of populations that shifted towards fewer home cooked meals and more ready-to-eat meals and eatingout $[1,3,4]$. It is worth highlighting that in our analyses, only food retailers whose main activity was meal delivery or take away were accounted for in the 'food delivery' category. However, it is well known that a major part of other type of food retailers such as restaurants and pizzerias, besides offering on-site table service, also offer 


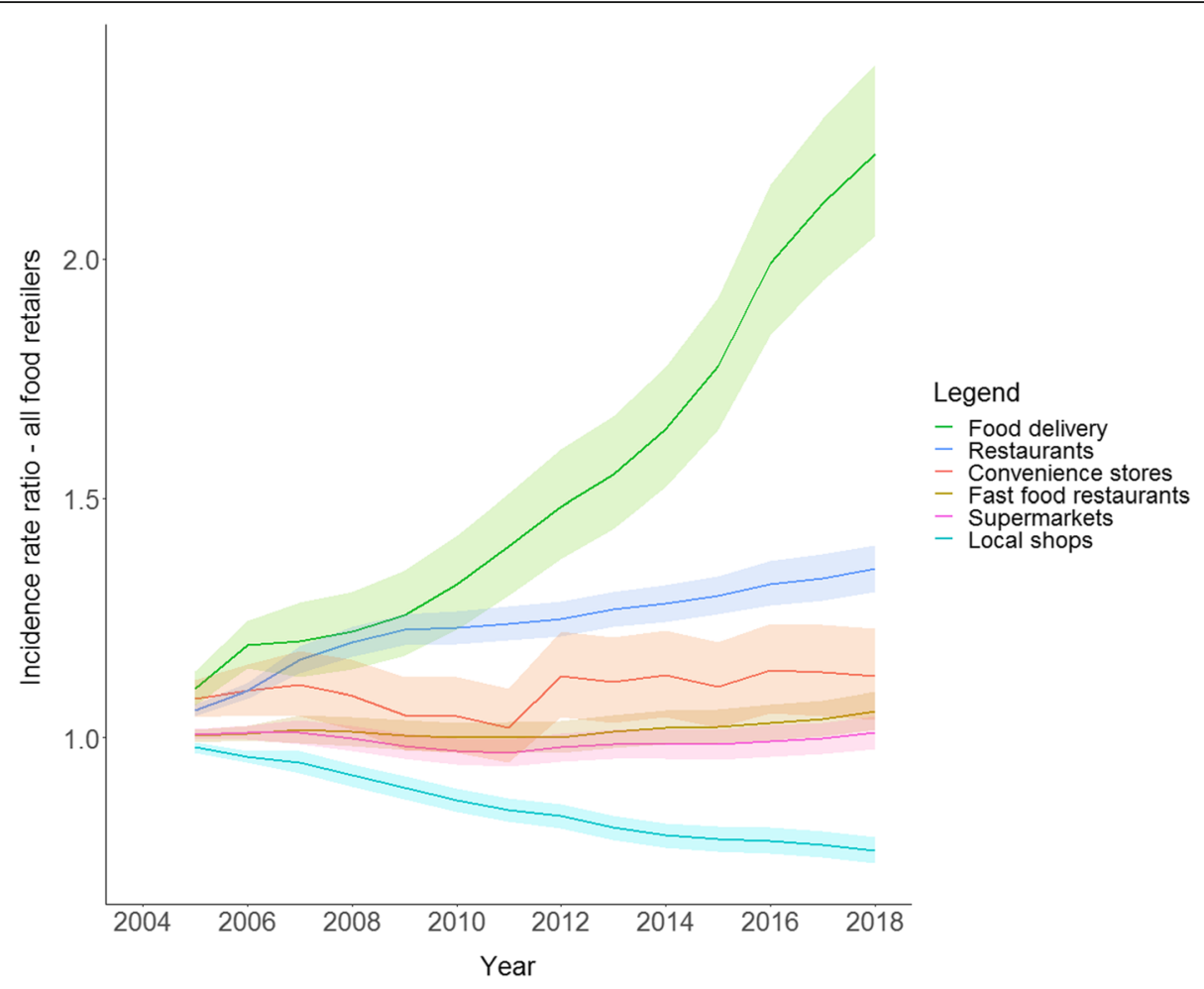

Fig. 1 Incidence rate ratio and 95\% confidence interval for average change in the neighbourhood counts of food retailers in the Netherlands. Coefficients were derived from negative binomial generalized estimating equations (GEE) analysis. Analyses were adjusted for the number of inhabitants per neighbourhoods

food delivery, either by their own or by making use of web/mobile applications. Therefore, the steep increase in the availability of food delivery places observed in this study is likely to be even higher. This scenario may potently lead to less healthy diets as eating out of home has been associated with poorer diets and weight gain, while eating home-cooked meals have been associated with better quality diets [18-20].

Disparities in the neighbourhood food environment and access to food have been documented before [21, $22]$, and there is convincing evidence from crosssectional studies, especially from the US, that residents of lower SES neighbourhoods have higher access to food retailers selling unhealthy foods such as fast foods, and lower access to food retailers selling healthier options [22]. We found that availability of fast food restaurants was higher in the lowest SES neighbourhood over the entire study period. However, there was no significant difference in change in the availability of fast food restaurants and food delivery outlets across neighbourhood SES and urbanisation categories. This suggests that there was no evidence for increasing disparities in access to fast food in the Dutch foodscape in the analysed period. This is in contrast with a study from the UK which found a greater increase in the availability of fast food restaurants and food delivery outlets in lower SES areas, enlarging socioeconomic differences in the access to food retailers [12]. Evidence from the US showed that residents of lower SES areas had the greater access to fast food retailers over a 40 year-period, however, since more affluent areas had a more steep increase in access to fast food retailers, differences between different strata of neighbourhood SES decreased over time [11]. A significant change, however, was found in our study for an increase in the availability of convenience stores and supermarkets in the lowest SES neighbourhoods.

A tendency towards an increase in access to supermarkets across lower SES areas was also found in previous research $[11,12]$. This may be due to the fact that it is more expensive for owners to open and maintain stores in more affluent neighbourhoods where the price of real estate is higher. Supermarkets have been mostly considered a source of healthier food options and convenience stores have been considered a source of less healthy foods [23]. However, it is worth mentioning that in the Netherlands convenience stores are mostly small-scale supermarkets found mainly in train stations and shopping areas. These "mini-supermarkets" also offer a range of healthy products such as ready-to-eat salads and chopped fruits to take away. Therefore, based only on 


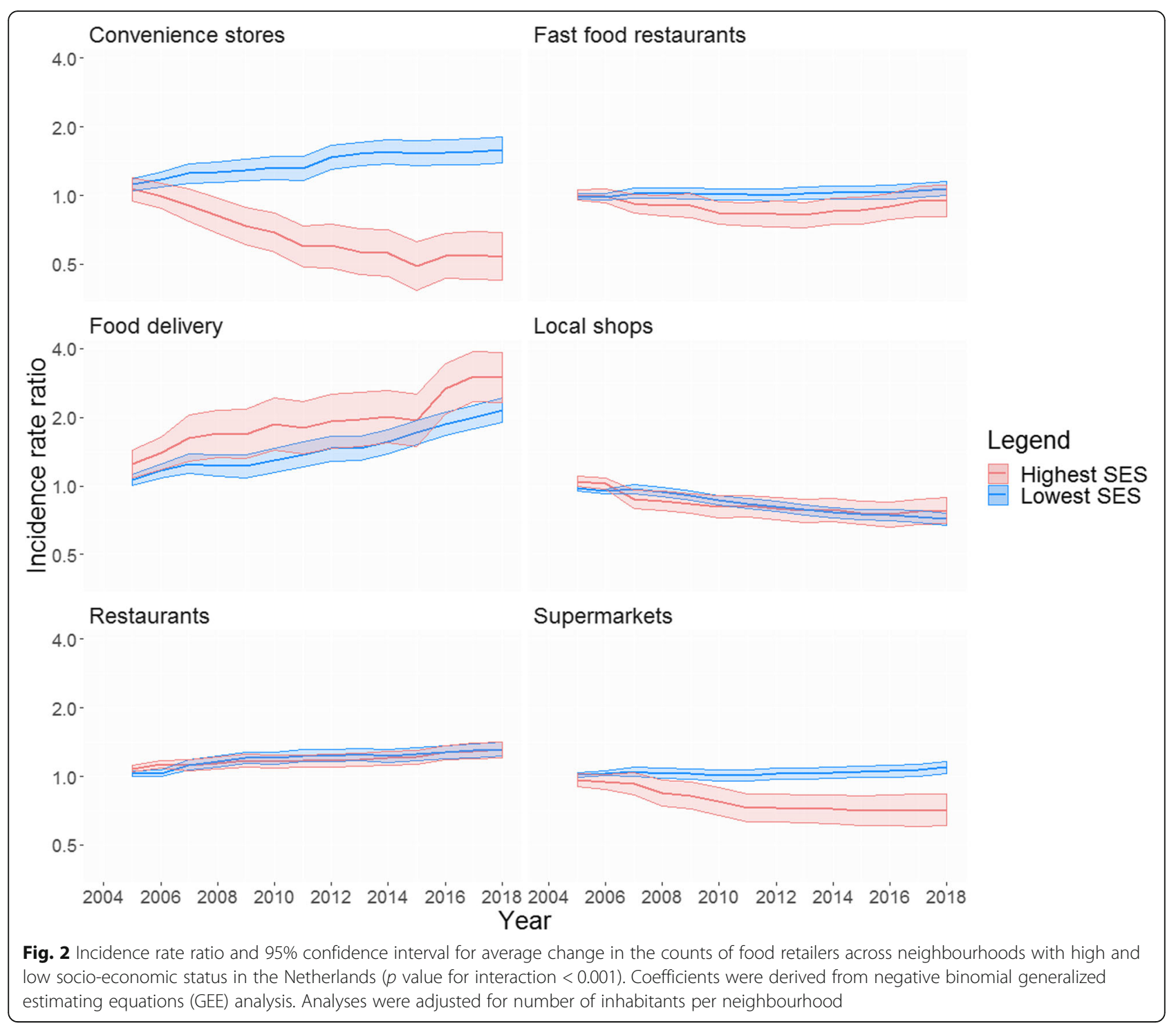

the location of food retailers (i.e., community food retail environment), we cannot conclude that lowest SES neighbourhoods developed a less healthy foodscape over this 14-year period. Insight into the consumer food retail environment (i.e., what is sold in each type of food outlet, and how the in-store offer of foods and drinks has changed over time) would therefore be of added value. It also needs to be noted that there was considerable overlap between the neighbourhood SES and urbanisation variables. That is, low SES neighbourhoods were often highly urbanised neighbourhoods, and high SES neighbourhoods were often low urbanised neighbourhoods. Observed SES-disparities may thus be attributable to urbanisation-disparities and vice versa, being hard to disentangle whether the differences found in our study are due to urban-rural or SES differences.
This study has some limitations. Although other relevant dimensions of the food environment such as opening times, quality and price of the foods offered in stores have probably changed over time [24], we had only information on the location of stores, and therefore analysed the foodscape solely in terms of type and geographic availability of food retailers. By using negative binomial GEE models, we were able to account for the over-dispersion of our count variables, which is an usual consequence of the a high number of zeros. However, this model does not account completely for the zero inflated nature of the data. A potential consequence of not accounting for zero inflation in the data is that statistically significant findings may be missed [25]. Therefore, although unlikely due our large sample of neighbourhoods, it is 


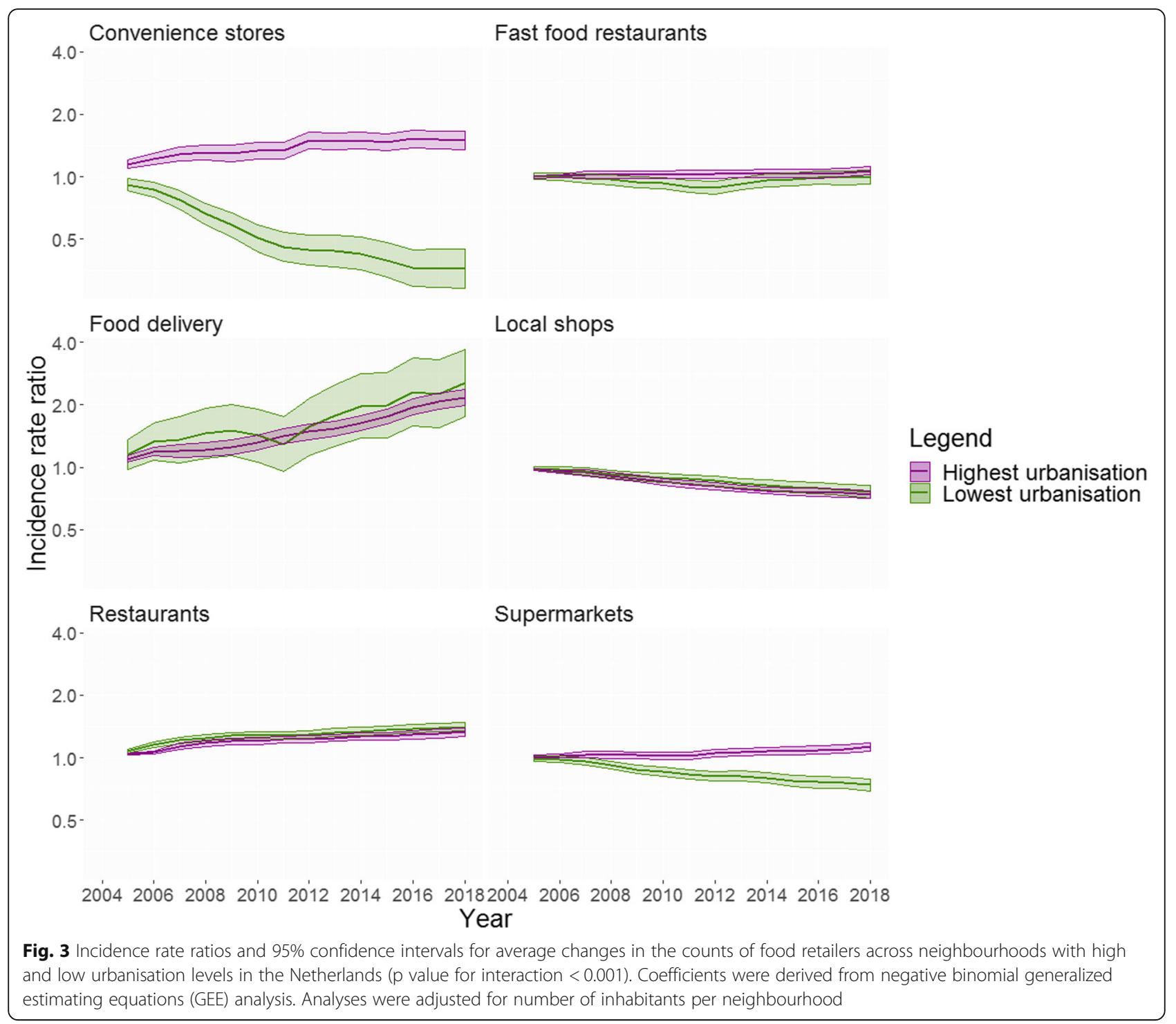

possible that we were unable to identify all the potential significant associations. We highlight the innovative aspect of this study as being the first to analyse the Dutch foodscape. As most previous studies could only analyse a few food retailers, in a limited area and using telephone or governmental directories data [10-12], it is a strength of our study that we analysed a wide range of food retailers, including food delivery outlets, using high quality objectively measured data across the entire country.

\section{Conclusions}

In conclusion, we observed important changes in the Dutch foodscape over a 14 years period. In general, the availability of food delivery outlets, restaurants and - to a lesser extent - fast food restaurants increased, while the availability of local food shops such as greengrocers, butchers and bakeries decreased. The only considerable differences across levels of neighbourhood SES and urbanisation were observed for convenience stores and supermarkets. Therefore, although disparities in the Dutch foodscape may not be so evident over the analysed period, in general, the foodscape has changed towards a higher availability of food retailers offering convenience and ready-to-eat foods. Similar, but context-dependent, changes may have taken place in other high-income countries as well, contributing to the global obesity epidemic. These findings can help policy makers aiming to promote a healthier food environment and obesity prevention. Future studies could link observed changes in the foodscape to national surveillance data on dietary behaviours and non-communicable disease trends. 


\section{Supplementary information}

Supplementary information accompanies this paper at https://doi.org/10. 1186/s12966-020-00944-5.

Additional file 1: Supplementary Table 1. Incidence rate ratio and 95\% confidence interval as derived from negative binomial generalized estimating equations (GEE) analysis. Coefficients represent the average change in the neighbourhood counts of fast food retailers in the Netherlands. Coefficients are presented for the totality of neighbourhoods, as well as according to neighbourhood socio-economic status (SES) and urbanisation levels. Supplementary Table 2. Incidence rate ratio and $95 \%$ confidence interval as derived from negative binomial generalized estimating equations (GEE) analysis. Coefficients represent the average change in the neighbourhood counts of food delivery outlets in the Netherlands. Coefficients are presented for the totality of neighbourhoods, as well as according to neighbourhood socio-economic status (SES) and urbanisation levels. Supplementary Table 3. Incidence rate ratio and 95\% confidence interval as derived from negative binomial generalized estimating equations (GEE) analysis. Coefficients represent the average change in the neighbourhood counts of supermarkets in the Netherlands. Coefficients are presented for the totality of neighbourhoods, as well as according to neighbourhood socio-economic status (SES) and urbanisation levels. Supplementary Table 4. Incidence rate ratio and $95 \%$ confidence interval as derived from negative binomial generalized estimating equations (GEE) analysis. Coefficients represent the average change in the neighbourhood counts of local food shops in the Netherlands. Coefficients are presented for the totality of neighbourhoods, as well as according to neighbourhood socio-economic status (SES) and urbanisation levels. Supplementary Table 5. Incidence rate ratio and $95 \%$ confidence interval as derived from negative binomial generalized estimating equations. Coefficients represent the average change in the neighbourhood counts of restaurants in the Netherlands. Coefficients are presented for the totality of neighbourhoods, as well as according to neighbourhood socio-economic status (SES) and urbanisation levels. (GEE) analysis. Supplementary Table $\mathbf{6}$. Incidence rate ratio and 95\% confidence interval as derived from negative binomial generalized estimating equations (GEE) analysis. Coefficients represent the average change in the neighbourhood counts of convenience stores in the Netherlands. Coefficients are presented for the totality of neighbourhoods, as well as according to neighbourhood socio-economic status (SES) and urbanisation levels.

\section{Abbreviations}

SES: Socioeconomic status; CBS: Central Bureau of Statistics; GEE: Generalized estimating equations; IRR: Incidence rate ratio; $\mathrm{km}^{2}$ : Square-kilometres; 95\% Cl: 95\% confidence intervals

\section{Acknowledgements}

We are grateful to Locatus for providing geographical data on retailers' locations in the Netherlands. The agencies cited here had no role in the design, analysis or writing of this article.

\section{Authors' contributions}

MGMP, JDM, NdB, JWJB AND JL contributed to study design. JDM was responsible for data acquisition. MGMP performed the data analysis and drafted the manuscript supervised by JDM, JWJB, JB AND JL. All authors read, provided feedback, and approved the final submitted version of the manuscript.

\section{Funding}

MGMP has a grant from the Brazilian higher education agency CNPq (National Council for Scientific and Technological Development) as part of Science Without Borders Program, Process number 233850/2014-7. JDM's work was funded by an NWO VENI grant on "Making the healthy choice easier - role of the local food environment" (grant number 451-17-032).

\section{Availability of data and materials}

The data that support the findings of this study are available from Locatus ${ }^{\oplus}$ but restrictions apply to the availability of these data, which were used under license for the current study, and so are not publicly available. Data are however available from the authors upon reasonable request and with permission of Locatus $^{\oplus}$.

\section{Ethics approval and consent to participate}

Not applicable.

\section{Consent for publication}

Not applicable.

\section{Competing interests}

The authors declare that they have no competing interests.

\section{Author details}

${ }^{1}$ Department of Epidemiology and Biostatistics, Amsterdam Public Health Research Institute, Amsterdam UMC, Vrije Universiteit Amsterdam, de Boelelaan 1089A, 1081, BT, Amsterdam, The Netherlands. ${ }^{2} J u l i u s$ Centre for Health Sciences and Primary Care, University Medical Centre Utrecht, Universiteitsweg 100, 3584, CG, Utrecht, The Netherlands. ${ }^{3}$ Amsterdam School of Communication Research (ASCoR), University of Amsterdam, P.O. Box 1, 3720, BA, Bilthoven, the Netherlands. ${ }^{4}$ Faculty of Geosciences, Utrecht University, Princetonlaan 8a, 3584, CB, Utrecht, The Netherlands.

Received: 13 August 2019 Accepted: 9 March 2020

Published online: 20 March 2020

\section{References}

1. Popkin BM. Global changes in diet and activity patterns as drivers of the nutrition transition. Nestle Nutr Workshop Ser Pediatr Program. 2009;63:110; discussion -4, 259-68. https://doi.org/10.1159/000209967.

2. Malik VS, Popkin BM, Bray GA, Despres JP, Willett WC, Hu FB. Sugarsweetened beverages and risk of metabolic syndrome and type 2 diabetes. Diabetes Care. 2010;33(11):2477-83. https://doi.org/10.2337/dc10-1079.

3. Monteiro CA, Moubarac JC, Cannon G, Ng SW, Popkin B. Ultra-processed products are becoming dominant in the global food system. Obes Rev. 2013:14:21-8. https://doi.org/10.1111/obr.12107.

4. Smith LP, Ng SW, Popkin BM. Trends in US home food preparation and consumption: analysis of national nutrition surveys and time use studies from 1965-1966 to 2007-2008. Nutr J. 2013;12. doi:Artn 45 https://doi.org/ 10.1186/1475-2891-12-45.

5. Brug J. Determinants of healthy eating: motivation, abilities and environmental opportunities. Fam Pract. 2008;25(Suppl 1):i50-5. https://doi. org/10.1093/fampra/cmn063.

6. Story M, Kaphingst KM, Robinson-O'Brien R, Glanz K. Creating healthy food and eating environments: policy and environmental approaches. Annu Rev Public Health. 2008;29:253-72. https://doi.org/10.1146/annurev.publhealth. 29.020907 .090926$.

7. Giskes K, van Lenthe F, Avendano-Pabon M, Brug J. A systematic review of environmental factors and obesogenic dietary intakes among adults: are we getting closer to understanding obesogenic environments? Obes Rev. 2011; 12(501):e95-e106. https://doi.org/10.1111/j.1467-789X.2010.00769.x.

8. Lake AA. Neighbourhood food environments: food choice, foodscapes and planning for health. Proc Nutr Soc. 2018;77(3):239-46. https://doi.org/10. 1017/S0029665118000022.

9. Swinburn B, Egger G, Raza F. Dissecting obesogenic environments: the development and application of a framework for identifying and prioritizing environmental interventions for obesity. Prev Med. 1999;29(6 Pt 1):563-70. https://doi.org/10.1006/pmed.1999.0585.

10. Filomena S, Scanlin K, Morland KB. Brooklyn, New York foodscape 20072011: a five-year analysis of stability in food retail environments. Int J Behav Nutr Phys Act. 2013;10:46. https://doi.org/10.1186/1479-5868-10-46.

11. James P, Seward MW, James O'Malley A, Subramanian SV, Block JP. Changes in the food environment over time: examining 40 years of data in the Framingham heart study. Int J Behav Nutr Phys Act. 2017;14(1):84. https:// doi.org/10.1186/s12966-017-0537-4.

12. Maguire ER, Burgoine T, Monsivais P. Area deprivation and the food environment over time: a repeated cross-sectional study on takeaway outlet density and supermarket presence in Norfolk, UK, 1990-2008. Health Place. 2015;33:142-7. https://doi.org/10.1016/j.healthplace.2015.02.012.

13. Richardson AS, Meyer KA, Howard AG, Boone-Heinonen J, Popkin BM, Evenson KR, et al. Neighborhood socioeconomic status and food environment: a 20-year longitudinal latent class analysis among CARDIA 
participants. Health Place. 2014;30:145-53. https://doi.org/10.1016/j. healthplace.2014.08.011.

14. Statistiek C-CBvd. Obesity rate in the Netherlands lower than in other OECD countries. CBS, Netherlands. 2011. http://www.cbs.nl/en-gb/artikelen/ nieuws/2011/47/obesity-rate-in-the-netherlands-lower-than-in-other-oecdcountries. 2019

15. Dekker LH, Rijnks RH, Strijker D, Navis GJ. A spatial analysis of dietary patterns in a large representative population in the north of the Netherlands - the lifelines cohort study. Int J Behav Nutr Phys Act. 2017; 14(1):166. https://doi.org/10.1186/s12966-017-0622-8.

16. Poelman M, Strak M, Schmitz O, Hoek G, Karssenberg D, Helbich M, et al. Relations between the residential fast-food environment and the individual risk of cardiovascular diseases in the Netherlands: a nationwide follow-up study. Eur J Prev Cardiol. 2018;25(13):1397-405. https://doi.org/10.1177/ 2047487318769458.

17. Moudon AV, Cook AJ, Ulmer J, Hurvitz PM, Drewnowski A. A neighborhood wealth metric for use in health studies. Am J Prev Med. 2011;41(1):88-97. https://doi.org/10.1016/j.amepre.2011.03.009.

18. Lachat C, Nago E, Verstraeten R, Roberfroid D, Van Camp J, Kolsteren P. Eating out of home and its association with dietary intake: a systematic review of the evidence. Obes Rev. 2012;13(4):329-46. https://doi.org/10. 1111/j.1467-789X.2011.00953.X.

19. Mills $\mathrm{S}$, Brown $\mathrm{H}$, Wrieden W, White M, Adams J. Frequency of eating home cooked meals and potential benefits for diet and health: cross-sectional analysis of a population-based cohort study. Int J Behav Nutr Phys Act. 2017;14(1):109. https://doi.org/10.1186/s12966-017-0567-y.

20. Nago ES, Lachat CK, Dossa RA, Kolsteren PW. Association of out-of-home eating with anthropometric changes: a systematic review of prospective studies. Crit Rev Food Sci Nutr. 2014;54(9):1103-16. https://doi.org/10.1080/ 10408398.2011.627095.

21. Ball K, Lamb KE, Costa C, Cutumisu N, Ellaway A, Kamphuis CB, et al. Neighbourhood socioeconomic disadvantage and fruit and vegetable consumption: a seven countries comparison. Int J Behav Nutr Phys Act. 2015;12:68. https://doi.org/10.1186/s12966-015-0229-x.

22. Black C, Moon G, Baird J. Dietary inequalities: what is the evidence for the effect of the neighbourhood food environment? Health Place. 2014;27:22942. https://doi.org/10.1016/j.healthplace.2013.09.015.

23. Woodruff RC, Raskind IG, Harris DM, Gazmararian JA, Kramer M, Haardorfer $R$, et al. The dietary impact of introducing new retailers of fruits and vegetables into a community: results from a systematic review. Public Health Nutr. 2018;21(5):981-91. https://doi.org/10.1017/S1368980017003226.

24. Glanz K, Sallis JF, Saelens BE, Frank LD. Healthy nutrition environments: concepts and measures. Am J Health Promot. 2005;19(5):330-3, ii. https:// doi.org/10.4278/0890-1171-19.5.330

25. Perumean-Chaney SE, Morgan C, McDowall D, Aban I. Zero-inflated and overdispersed: what's one to do? J Stat Comput Simul. 2013;83(9):1671-83. https://doi.org/10.1080/00949655.2012.668550.

\section{Publisher's Note}

Springer Nature remains neutral with regard to jurisdictional claims in published maps and institutional affiliations.

Ready to submit your research? Choose BMC and benefit from:

- fast, convenient online submission

- thorough peer review by experienced researchers in your field

- rapid publication on acceptance

- support for research data, including large and complex data types

- gold Open Access which fosters wider collaboration and increased citations

- maximum visibility for your research: over $100 \mathrm{M}$ website views per year

At BMC, research is always in progress.

Learn more biomedcentral.com/submissions 